\section{Digitized nonobjects for use with the Apple Macintosh computer}

\section{JOHN O. BROOKS III and LAURA L. BIEBER Rice University, Houston, Texas}

Research involving lexical decision tasks has played a major role in conceptualizations of both perceptual processes and semantic decisions (e.g., Andrews, 1986; Bleasdale, 1987; Kroll \& Merves, 1986; Kroll \& Potter, 1984; Scarborough, Cortese, \& Scarborough, 1977). In a typical lexical decision task, subjects see a briefly presented string of letters and are asked to decide whether the letters form an English word or a nonword. Recently, Kroll and Potter (1984) introduced the object decision task, which is analogous to the lexical decision task in that subjects see a briefly presented drawing and are asked to decide whether the drawing is of a real object or a nonobject. As shown in Figure 1, a nonobject is a nonsense figure constructed from elements of real objects. Findings obtained from the object decision task are important for both theories of memory (Kroll \& Potter, 1984; Kroll \& Venugopal, 1984) and theories of perception (Biederman, 1985).

Typically, researchers have used tachistoscopes to present pictorial stimuli. Personal computers, however, are now capable of presenting pictorial stimuli and are more versatile than a tachistoscope because they allow more variation in experimental design. We have made Kroll and Potter's (1984) nonobject stimuli available in a form suitable for presentation on the Apple Macintosh computer. By using the computerized versions of the nonobjects in conjunction with Brooks's (1985) computerized versions of Snodgrass and Vanderwart's (1980) line drawings of real objects, researchers may now take advantage of the Macintosh's capabilities in object decision experiments. Note, however, that researchers should choose their object drawings carefully, for it is conceivable that subtle artistic differences between the object drawings and the nonobject drawings could affect the outcome of an experiment.

Description of the Stimuli. The set of stimuli comprises the 88 nonobjects published by Kroll and Potter (1984). The nonobjects were digitized with ThunderScan, a high-quality digitizer for the Macintosh, and each stimulus was edited with a graphics editor to achieve maximum clarity. The digitized stimuli are approximately the same size as the actual stimuli that Kroll and Potter (1984) used in their experiments and are therefore larger than the stimuli provided in Kroll and Potter's paper. The size of

This work was supported in part by a National Science Foundation Graduate Fellowship to the first author. The authors would like to thank Judith F. Kroll for providing a copy of the actual stimuli used by Kroll and Potter (1984). The authors' mailing address is Department of Psychology, Rice University, Houston, TX 77251. a stimulus, however, can be altered easily by using Macintosh $\mathrm{ROM}$ routines.

For each nonobject drawing, Kroll and Potter (1984) provided a rating of the degree to which it resembled a real object and the mean time required to make an object decision. Because the digitized versions of the stimuli are fairly accurate representations of the original stimuli, it is reasonable to assume that Kroll and Potter's ratings hold for the digitized stimuli as well.

Format of the Stimuli. The set of nonobject drawings is provided in MacPaint files, which may be created by the graphics editors MacPaint or SuperPaint. All other graphics editors for the Macintosh currently on the market are capable of opening files that are in MacPaint format. A graphics editor allows researchers to customize easily the nonobjects to suit the needs of a particular experiment. The ordering of the nonobjects in the MacPaint files conforms to the ordering of Kroll and Potter's (1984) stimuli, so that the ratings for a particular nonobject can be found easily.

With high-level programming languages, such as BASIC and Pascal, it is most convenient to access the stimuli if they are stored as either encoded graphics instructions or bit images. Although it is fairly easy to convert graphics in MacPaint format into encoded graphics instructions (Brooks, in press), the nonobject drawings are provided in both formats. When stimuli are stored as encoded graphics instructions, researchers can use Macintosh ROM routines that permit powerful manipulations of graphics (Brooks, 1987; Lane \& Ashby, 1987). Microsoft BASIC 3.0, for example, includes a machine

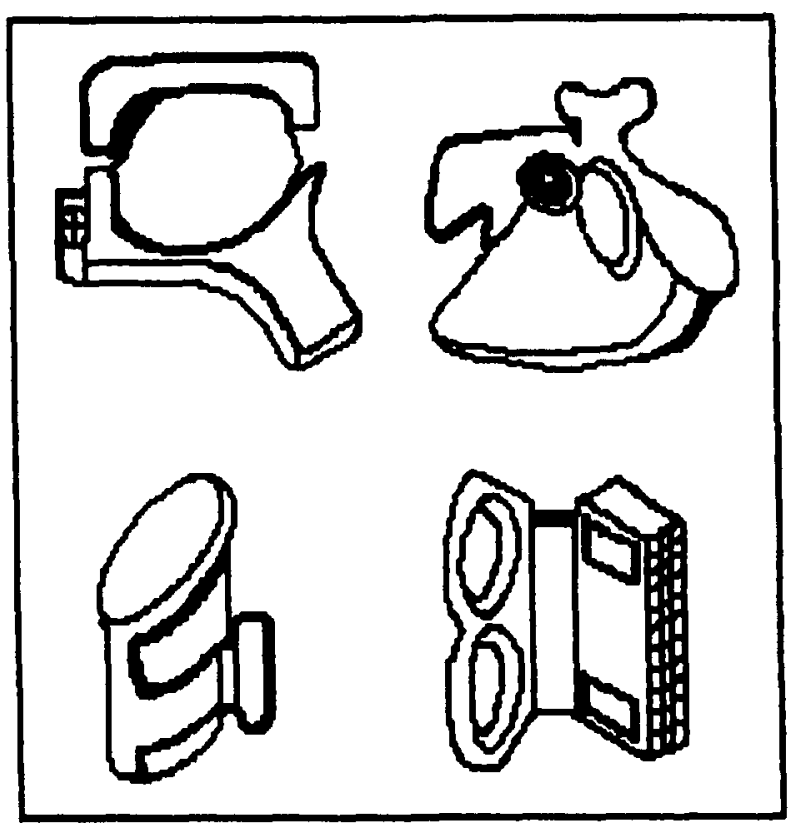

Figure 1. Four examples of digitized nonobjects. 
language library that allows progammers to use almost all of the graphics routines of the Macintosh ROM.

In some instances, it is convenient to use stimuli in the form of bit images (i.e., pixel-based representations). Bit images can be generated from encoded graphics instructions by using Microsoft BASIC (see Brooks, 1985, 1987). Once in the form of bit images, stimuli can be changed in a number of ways, such as by using machine language routines to degrade them (e.g., Brooks, 1987), as shown in Figure 2.

Hardware and Software Requirements. An Apple Macintosh computer is required to use the stimuli. Any graphics editor (e.g., Canvas, MacPaint, or SuperPaint) may be used to edit the digitized nonobjects. The stimuli may be presented on the Macintosh by the application HyperCard (which is supplied with the Macintosh) or by most programming languages.

Availability. The files containing the 88 digitized nonobjects, and the sample programs are provided on an

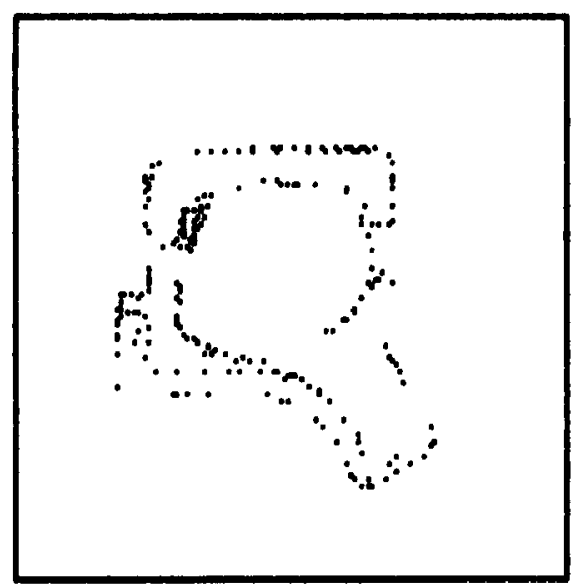

Figure 2. A nonobject that has been visually degraded with a routine provided by Brooks (1987).
$800 \mathrm{~K}$ disk and may be obtained by sending $\$ 6$ to the authors.

\section{REFERENCES}

ANDREWS, S. (1986). Morphological influences on lexical access: Lexical or nonlexical effects? Journal of Memory \& Language, 25, 726-740.

Biederman, I. (1985). Human image understanding: Recent research and a theory. Computer Vision, Graphics, \& Image Processing, 32, 29-73.

BleASDAle, F. A. (1987). Concreteness-dependent associative priming: Separate lexical organization for concrete and abstract words. Journal of Experimental Psychology: Learning, Memory, \& Cognition, 13, 582-594.

Brooks, J. O., III. (1985). Pictorial stimuli for the Apple Macintosh computer. Behavior Research Methods, Instruments, \& Computers, 17, 409-410.

Brooks, J. O., III. (1987). Enhancing and degrading visual stimuli. Behavior Research Methods, Instruments, \& Computers, 19, 260-269.

Brooks, J. O., III. (in press). Microsoft BASIC 3.0: Scrapbook Mover. Nibble Mac.

Kroll, J. F., \& Merves, J. S. (1986). Lexical access for concrete and abstract words. Journal of Experimental Psychology: Learning, Memory, \& Cognition, 12, 92-107.

Kroll, J. F., PotTer, M. C. (1984). Recognizing words, pictures, and concepts: A comparison of lexical, object, and reality decisions. Journal of Verbal Learning \& Verbal Behavior, 23, 39-66.

Kroll, J. F., \& Venugopal, V. (1984, November). Lexical and object decisions in sentence context. Paper presented at the 25th Annual Meeting of the Psychonomic Society, San Antonio, TX.

LANe, D. M., AshbY, A. B. (1987). PsychLib: A library of machinelanguage routines for controlling psychology experiments on the Apple Macintosh computer. Behavior Research Methods, Instruments, \& Computers, 19, 246-248.

Scarborough, D. L., Cortese, C., \& Scarborough, H. S. (1977). Frequency and repetition effects in lexical memory. Journal of Experimental Psychology: Human Perception \& Performance, 3, 1-17.

Snodgrass, J. G., Vanderwart, M. A. (1980). A standardized set of 260 pictures: Norms for name agreement, image agreement, familiarity, and visual complexity. Journal of Experimental Psychology: Human Learning \& Memory, 6, 174-215.

(Revision accepted for publication May 20, 1988.) 